\title{
Analgesics Improve the Gait of Lame Dairy Cattle
}

\author{
F. C. Flower, ${ }^{\star}$ M. Sedlbauer, ${ }^{\star}$ E. Carter, ${ }^{*}$ M. A. G. von Keyserlingk, ${ }^{\star}$ D. J. Sanderson, $†$ and D. M. Weary ${ }^{\star 1}$ \\ *Animal Welfare Program, Faculty of Food and Land Systems, and \\ †School of Human Kinetics, University of British Columbia, Vancouver, Canada, V6T 1 Z4
}

\begin{abstract}
Pain associated with injuries of the hoof and surrounding tissues is an important cause of lameness. The objective was to detect the attributes of impaired gait that are associated with pain. In 3 separate experiments, lactating Holstein cows $(\mathrm{n}=20 ; \mathrm{n}=21 ; \mathrm{n}=$ 27) diagnosed with varying degrees of gait impairment were injected i.m. (Exp. 1 and 2) or i.v. (Exp. 3) with the analgesic ketoprofen at $0,0.3,1.5$, or $3.0 \mathrm{mg} / \mathrm{kg}$ of BW. Gait was evaluated subjectively using a numerical rating system (NRS; varying from 1 to 5 ) and 6 specific gait attributes (back arch, tracking up, joint flexion, asymmetric steps, head bob, and reluctance to bear weight). Each experiment was divided into 3 phases each lasting $3 \mathrm{~d}$ : before treatment, after treatment, and during treatment with daily injections of ketoprofen. The NRS improved by $0.25 \pm 0.05$ with the highest dose of ketoprofen. Although none of the specific gait attributes showed a consistent response to treatment, there was an interaction between dose and experiment for asymmetric steps and reluctance to bear weight; in Exp. 1, but not Exp. 2 and 3, cow steps were more symmetrical (improving by $7.16 \pm 1.02$ ), and cows distributed their weight more evenly (improving by 5.84 \pm 1.13 ) at the highest doses of ketoprofen. These results indicated that the NRS was more sensitive than the specific gait attributes in assessing differences in gait associated with pain. The results showed that ketoprofen has only a modest effect on gait, indicating either that this drug has little effect on pain due to lameness or that much variation in NRS was due to factors other than pain.
\end{abstract}

Key words: dairy cattle, lameness, pain, nonsteroidal antiinflammatory drug

\section{INTRODUCTION}

The importance of lameness in dairy cattle and its effect on production and animal welfare is increasingly

Received December 20, 2007.

Accepted March 31, 2008.

${ }^{1}$ Corresponding author: danweary@interchange.ubc.ca recognized (Kelton et al., 1998; Rushen, 2001), with studies reporting incidences as high as 55\% (Clarkson et al., 1996). Lameness can affect the behavior of cows (Galindo and Broom, 2002; O'Callaghan et al., 2003) and result in reduced milk production (Green et al., 2002), delayed reproduction (Garbarino et al., 2004), and involuntary culling (Gröhn et al., 2003).

Deviations in gait are thought to be due to the pain associated with injuries on the hooves and legs (Whay et al., 1998). Nonetheless, much of the variation in both objective and subjective measures of gait could be attributed to factors other than pain, for instance, ligament or nerve damage (Greenough et al., 1981), and physical constraints such as udder distension (Flower et al., 2006). One method of determining which aspects of gait are specifically associated with pain is to measure changes in the gait of lame cows in response to treatment with an analgesic (Rutherford, 2002).

Studies on horses and broilers used subjective and objective diagnostic approaches to evaluate analgesics (Owens et al., 1995; McGeown et al., 1999) but have not identified gait characteristics associated with pain. Rushen et al. (2007) found that cows afflicted with a hoof injury and treated with an injection of the local anesthetic lidocaine into the hoof bulb showed reduced numerical rating scores (NRS), indicating that pain in the hoof could be mitigated using a nerve block. In contrast to the local effects of lidocaine, nonsteroidal antiinflammatory drugs (NSAID) provide systemic effects, without causing the sedation and tranquilization associated with opioid-based analgesics. The advantage of this approach is that it could mitigate pain throughout the body, including upper-limb injuries.

The NSAID ketoprofen is effective in controlling pain after surgical procedures in cattle (Ting et al., 2003; Milligan et al., 2004) and is licensed for use in dairy cows in many jurisdictions with no milk withdrawal. The aim of this study was to identify changes in gait due to pain controlled by ketoprofen. A secondary aim was to identify which gait measures were most sensitive to the effect of pain by monitoring changes in a composite gait score and 6 separate attributes associated with impaired gait. 


\section{MATERIALS AND METHODS}

\section{Cows and Management}

This study comprised 3 separate experiments conducted at University of British Columbia's Dairy Education and Research Centre in Agassiz, British Columbia, in 2004 and 2005. Cows were milked twice daily and fed a TMR formulated to meet the nutrient requirements appropriate for their stage of lactation as recommended by NRC (2001). Water was available ad libitum from self-filling water troughs. All animals were cared for according to a protocol approved by the University of British Columbia Animal Care Committee.

Twenty lactating Holsteins [(mean \pm SD) BW: $680 \pm$ $67 \mathrm{~kg}$; parity: $3.5 \pm 2.3$; DIM: $190 \pm 97 \mathrm{~d}$; milk production: $41.2 \pm 10.9 \mathrm{~kg} / \mathrm{d}]$ were used in Exp. 1; 21 lactating Holsteins (BW: $665 \pm 53 \mathrm{~kg}$; parity: $3.2 \pm 1.2$; DIM: 140 $\pm 57 \mathrm{~d}$; milk production $42.2 \pm 12.5 \mathrm{~kg} / \mathrm{d}$ ) were used in Exp. 2; and 27 lactating Holsteins (BW: $691 \pm 65 \mathrm{~kg}$; parity: $4.1 \pm 1.6$; DIM: $139 \pm 68 \mathrm{~d}$; milk production: 43.5 $\pm 11.1 \mathrm{~kg} / \mathrm{d}$ ) were used in Exp. 3. Of the 68 cows used, 6 cows were used more than once ( 2 cows used in Exp. 1 were used in Exp. 3, and 4 cows used in Exp. 1 were used in Exp. 2).

\section{Treatments}

Before the start of each experiment, cows were gaitscored using a NRS from 1 to 5 following Flower and Weary (2006). Each animal was assigned to a dose of ketoprofen (Anafen, Merial Canada Inc., Montreal, Canada), such that treatment groups were balanced according to initial gait score, BW, parity, and DIM. Each study lasted $9 \mathrm{~d}$ : a 3 -d pretreatment phase (before), 3-d treatment phase (during), and 3-d posttreatment phase (after).

To ensure that the ketoprofen had time to take effect, cows were treated $1 \mathrm{~h}$ before gait scoring when using i.m. injections (Exp. 1 and 2) and 15 min before when using i.v. injections in Exp. 3. On treatment days, each animal was held in a headlock and received $30 \mathrm{~mL}$ of saline solution combined with the assigned concentration of ketoprofen. For Exp. 1 and 2, dosages of ketoprofen were $0.3,1.5$, and $3.0 \mathrm{mg} / \mathrm{kg}$ of BW. For Exp. 3, dosages of ketoprofen were $0,1.5$, and $3.0 \mathrm{mg} / \mathrm{kg}$ of BW. Volumes of each dosage were adjusted separately for each cow dependent on BW.

\section{Subjective Gait Assessment}

Cows were subjected to all aspects of the experimental procedure, with the exception of NSAID administration, at least $7 \mathrm{~d}$ before the data collection period to allow animals to habituate. After milking, cows were administered the ketoprofen treatments and held 15 min to $1 \mathrm{~h}$ as described above. Cows were then walked individually down a 40-m long grooved concrete alley and recorded using a video camera placed $10 \mathrm{~m}$ from the alley, with the lens axis perpendicular to the walking direction of the cows. At the beginning of each recording session, the alley was cleaned with an automatic scraper.

In each experiment, a different trained observer scored cow gait using the video recordings and a 1 to 5 NRS. For example, gait was scored as 1 (sound) when cows showed smooth and fluid movement, a flat back, steady head carriage, hind hooves fell on or in front of the imprint left by the forehooves (tracking up), joints flexed freely, gait was symmetrical, and all 4 legs appeared to bear weight equally. Gait was scored as 3 (clinically lame) when cows had an arched back, their ability to move freely was compromised, head carriage was steady, hind hooves did not track up, joints showed signs of stiffness, and gait was asymmetrical with a slight limp. Gait was scored as 5 (severely lame) when cows had an extremely arched back, needed vigorous encouragement to move, had an obvious head bob, poor tracking up with short strides, obvious joint stiffness, walked with very hesitant and deliberate strides, gait was asymmetrical, and they were unable to bear weight on one or more limbs (Flower and Weary, 2006).

Observers were experienced in gait scoring and had been trained using the same training tapes. In addition, 6 specific gait attributes (back arch, head bob, tracking up, joint flexion, asymmetric steps, and reluctance to bear weight) were scored using 100 -unit continuous visual analog scales (Flower and Weary, 2006). The ends of the visual analog scales had a description of the extreme forms of the condition. For example, degree of back arch was defined as flat at one end (0) of the scale and convex at the other end (100), where convex represented the most extreme back arch the observer had seen in their experience. The observer recorded directly on a computer screen a position on the scale that represented the severity of the attribute. Joint flexion and asymmetric steps were not assessed in Exp. 3 , because at the time this experiment took place, new work suggested that these measures could only be assessed with lower intraobserver reliability (Flower and Weary, 2006). All observers were blind to day of experiment and treatment group. Observers scored each video clip twice for each of the gait attributes and twice for the NRS.

\section{Statistical Analysis}

Observations on multiple days were averaged to form a mean value per cow per phase per experiment. Values 
Table 1. Least squares means $\pm \mathrm{SE}$ treatment differences from baseline values for the numerical rating score (NRS) and each of the individual gait attributes ${ }^{1}$

\begin{tabular}{|c|c|c|c|c|c|c|c|}
\hline \multirow[b]{2}{*}{ Item } & \multicolumn{4}{|c|}{ Ketoprofen dose (mg/kg of BW) } & \multicolumn{3}{|c|}{$P$-value } \\
\hline & 0 & 0.3 & 1.5 & 3.0 & Dose & Experiment & $\begin{array}{c}\text { Dose } \times \\
\text { experiment }\end{array}$ \\
\hline Back arch & $0.90 \pm 1.82$ & $1.38 \pm 1.38$ & $1.20 \pm 1.00$ & $1.98 \pm 0.96$ & NS & NS & NS \\
\hline Tracking up & $-0.70 \pm 0.94$ & $0.45 \pm 0.74$ & $-0.74 \pm 0.49$ & $0.43 \pm 0.47$ & NS & 0.0003 & NS \\
\hline Joint flexion & - & $0.90 \pm 0.54$ & $1.23 \pm 0.54$ & $1.70 \pm 0.50$ & NS & 0.0003 & NS \\
\hline Asymmetric steps & - & $0.65 \pm 0.74$ & $0.57 \pm 0.74$ & $3.12 \pm 0.69$ & - & - & 0.0012 \\
\hline
\end{tabular}

${ }^{1}$ Main effects are not reported where the interaction is significant.

were initially compared across the 2 baseline phases (before vs. after; $1 \mathrm{df}$ ) using a paired $t$-test. No differences between baseline phases were found (mean NRS \pm SEM was identical for the before and after phases; $3.4 \pm 0.1$ ), allowing the pooling of values from these 2 phases to create an overall baseline value for each experiment.

The mean of the treatment phase was subtracted from the mean of the combined baseline to calculate a difference value for each cow. The resulting difference scores were regressed against the dose of the analgesic to test for a linear relationship between the 2 measures. All statistical analyses were performed using the GLM procedure in SAS, with dose (1 df), experiment ( $2 \mathrm{df})$, and a dose $\times$ experiment interaction $(2 \mathrm{df})$ all tested against the residual error term (62 df).

Subsamples of video clips from the 3 experiments $(\mathrm{n}=$ $37, \mathrm{n}=21$, and $\mathrm{n}=81$ ) were rescored to test intraobserver consistency. At least $2 \mathrm{~d}$ were allowed between scoring and rescoring. Scores were regressed against each other, and the coefficient of determination $\left(R^{2}\right)$ was calculated.

\section{RESULTS}

Four doses of ketoprofen were used over the 3 experiments. As expected, animals given saline (i.e., the 0 $\mathrm{mg} / \mathrm{kg}$ of BW ketoprofen) or the lowest dose of ketoprofen $(0.3 \mathrm{mg} / \mathrm{kg}$ of BW $)$ showed little or no improvement in gait (Table 1).

Cows given higher doses of ketoprofen (1.5 or $3.0 \mathrm{mg} /$ $\mathrm{kg}$ of BW) showed a clear dose-dependent improvement in NRS (Figure 1; $\mathrm{R}^{2}=0.32 ; \mathrm{n}=68 ; P=0.001$ ). None of the 6 specific gait attributes showed a consistent response to treatment. An interaction between dose and experiment was found for asymmetric steps and reluctance to bear weight. In Exp. 1, cows showed improvements in these gait attributes with greater doses of ketoprofen: steps were more symmetrical (mean \pm SEM improvement relative to baseline at $0.3,1.5$, and 3.0 $\mathrm{mg} / \mathrm{kg}$ of BW: $1.63 \pm 1.03 ; 1.24 \pm 1.11 ; 7.16 \pm 1.02$, respectively), and cows distributed their weight more evenly at higher doses of ketoprofen $(0.85 \pm 1.13 ; 1.49$ $\pm 1.22 ; 5.84 \pm 1.13$, respectively). But no such effects were observed in Exp. 2 or 3.

The subjective assessments of gait were reasonably consistent across multiple observations in each of the 3 experiments (Table 2). The NRS showed good intraobserver reliability, but individual gait attributes were more variable across the 3 experiments. Asymmetric steps and joint flexion were not recorded in Exp. 3 and tended to show lower levels of intraobserver reliability in Exp. 1 and 2.

\section{DISCUSSION}

The results provide evidence of dose-dependent changes in cattle lameness in response to treatment with analgesics, indicating that the NSAID ketoprofen mitigates pain associated with lameness in dairy cattle, although the magnitude of this effect was modest. For example, the difference in NRS between baseline and treatment phases was less than a quarter point, even

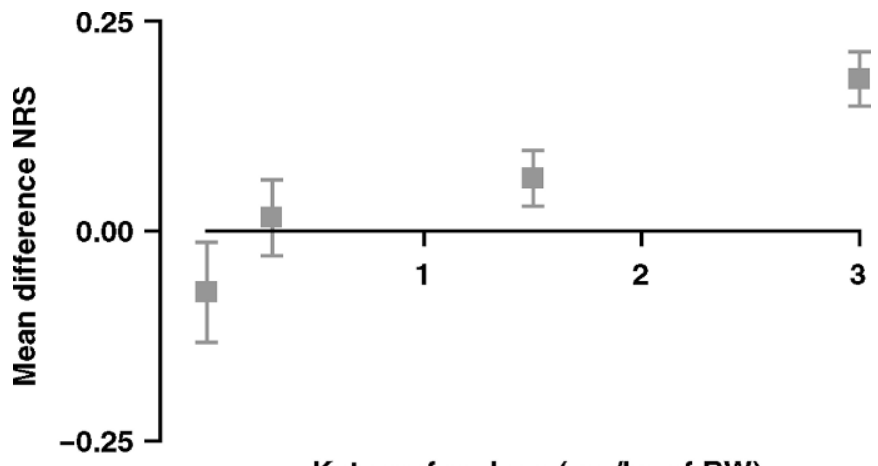

Ketoprofen dose (mg/kg of BW)

Figure 1. Mean $( \pm$ SEM) difference between baseline and treatment phases in the numerical rating score (NRS of 1 to $5 ; n=68$ ) plotted as a function of ketoprofen dose. 
Table 2. Coefficients of determination $\left(\mathrm{R}^{2}\right)$ for intraobserver consistency in the numerical rating score (NRS) and each of the 6 gait attributes ${ }^{1}$

\begin{tabular}{lccc}
\hline Item & Experiment 1 & Experiment 2 & Experiment 3 \\
\hline NRS & 0.98 & 0.95 & 0.78 \\
Back arch & 0.98 & 0.52 & 0.86 \\
Tracking up & 0.96 & 0.67 & 0.86 \\
Joint flexion & 0.78 & 0.45 & - \\
Asymmetric steps & 0.62 & 0.66 & - \\
Head bob & 0.83 & 0.94 & 0.75 \\
Reluctance to bear weight & 0.88 & 0.84 & 0.78 \\
\hline
\end{tabular}

${ }^{1}$ Coefficients were calculated separately for each of the 3 experiments using a subsample of observations ( $\mathrm{n}=37,21$, and 81 , respectively) that were scored twice.

at the highest dose of analgesic, a difference similar to the resolution of the scoring system. Similarly, Rushen et al. (2007) found a small reduction (0.3) in NRS after treatment of an injured hoof with local anesthetic. The modest effect of both the NSAID and the local block indicated that either 1) much variation in NRS was due to factors other than the pain experienced by the cow or 2) these drugs were marginally effective in treating the pain due to lameness. We encourage research on the combination of local blocks and systemic analgesics, because this approach could address the role of pain affecting the hoof, versus pain higher up the limb and elsewhere in the body.

The development and healing of hoof injuries, particularly sole hemorrhages, is a lengthy process (Kempson and Logue, 1993; Lischer et al., 2002), and cases of lameness often persist several months (Phillips, 1990). For example, Green et al. (2002) found that milk production of lame cows was reduced for up to 4 mo before and 5 mo after diagnosis of lameness, suggesting that cows may experience pain and alter their gait for months. These long-term changes in gait would likely cause hypertrophy of certain muscle groups, processes that would require weeks to reverse after the pain is removed. In other situations locomotor structures may be permanently damaged (e.g., injuries of tendons and ligaments). In both cases, little response to short-term treatment might be expected with analgesics.

A significant interaction was found between dose and experiment for 2 of the specific gait attributes: asymmetric steps and reluctance to bear weight. Both of these subjectively evaluated attributes reflected how the cow distributes its weight among its 4 legs. Rushen et al. (2007) measured weight bearing directly using force plates and found a more even weight distribution among the limbs when cows were administered a local anesthetic directly into the injured hoof.

Various hoof injuries and diseases afflict dairy cattle, from sole hemorrhages and ulcers to heel horn erosion and digital dermatitis. These conditions are frequently found on commercial dairy farms, but it is not clear how much pain was caused by these different ailments. In previous studies (Flower et al., 2005; Flower and Weary, 2006), pronounced changes were observed in gait for cows with sole ulcers but not for those with sole hemorrhages, suggesting that the latter were less painful during walking. It is possible that the gait measures used were only effective at detecting higher intensities of pain. The interaction between dose and experiment for asymmetric steps and reluctance to bear weight may have been due to cows being affected by different pathologies in each of these experiments. Further research is required using cows with specific hoof and leg ailments to determine the pain that these cause and how this pain affects gait.

Our ability to detect relatively subtle changes in gait was limited by the assessment method. The NRS showed intraobserver consistency and was effective at identifying cows with sole ulcers (Flower and Weary, 2006). Both the current study and Flower and Weary (2006) showed that at least some of the specific gait attributes can be rescored consistently, but both studies indicate that the specific gait attributes are less useful as indicators either of the pain due to lameness (current study) or the presence of sole ulcers (Flower and Weary, 2006). Hernandez-Mendo et al. (2007) compared a matched sample of lame cows, kept for 5 wk in either a freestall barn or on pasture. Gait improved rapidly for the cows on pasture, as measured using the NRS, but there was again no effect of treatment on specific gait attributes like back arch or head bob. Together these results indicate that composite scores such as the NRS offer more promise than measure of any one specific attribute.

\section{ACKNOWLEDGMENTS}

We thank the staff and students at the University of British Columbia Dairy Education and Research Centre, especially Allison Stewart, Lorna Baird, Trevor DeVries, Tomasz Grudnik, and Julie Woodward for their help. General support for the University of British 
Columbia Animal Welfare Program was provided by Canada's Natural Sciences and Engineering Research Council and by contributions from the Dairy Farmers of Canada, the British Columbia Dairy Foundation, members of the British Columbia Veterinary Medical Association, and many others (listed at http://www.landfood.ubc.ca/animalwelfare). The Slovene Human Resources Development and Scholarship Fund provided financial support to M. Sedlbauer while he completed his graduate work at the University of British Columbia. Ketoprofen was supplied by Merial Canada Inc., Montreal, Canada.

\section{REFERENCES}

Clarkson, M. J., D. Y. Downham, W. B. Faull, J. W. Hughes, F. J. Manson, J. B. Merritt, R. D. Murray, W. B. Russell, J. E. Sutherst, and W. R. Ward. 1996. Incidence and prevalence of lameness in dairy cattle. Vet. Rec. 138:563-567.

Flower, F. C., D. J. Sanderson, and D. M. Weary. 2005. Hoof pathologies influence kinematic measures of dairy cow gait. J. Dairy Sci. 88:3166-3173.

Flower, F. C., D. J. Sanderson, and D. M. Weary. 2006. Effects of milking on dairy cow gait. J. Dairy Sci. 89:2084-2089.

Flower, F. C., and D. M. Weary. 2006. Effect of hoof pathologies on subjective assessments of dairy cow gait. J. Dairy Sci. 89:139-146.

Galindo, F., and D. M. Broom. 2002. The effects of lameness on social and individual behaviour of dairy cows. J. Appl. Anim. Welf. Sci. 5:193-201.

Garbarino, E. J., J. A. Hernandez, J. K. Shearer, C. A. Risco, and W. W. Thatcher. 2004. Effect of lameness on ovarian activity in postpartum Holstein cows. J. Dairy Sci. 87:4123-4131.

Green, L. E., V. J. Hedges, Y. H. Schukken, R. W. Blowey, and A. J. Packington. 2002. The impact of clinical lameness on the milk yield of dairy cows. J. Dairy Sci. 85:2250-2256.

Greenough, P. R., F. J. MacCallum, and A. D. Weaver. 1981. Lameness in Cattle. 2nd ed. John Wright \& Sons Ltd., Bristol, UK.

Gröhn, Y. T., P. J. Rajala-Schultz, H. G. Allore, M. A. DeLorenzo, J. A. Hertl, and D. T. Galligan. 2003. Optimizing replacement of dairy cows: Modeling the effects of diseases. Prev. Vet. Med. 61:27-43.
Hernandez-Mendo, O., M. A. G. von Keyserlingk, D. M. Veira, and D. M. Weary. 2007. Effects of pasture on lameness in dairy cows. J. Dairy Sci. 90:1209-1214.

Kelton, D. F., K. D. Lissemore, and R. E. Martin. 1998. Recommendations for recording and calculating the incidence of selected clinical diseases of dairy cattle. J. Dairy Sci. 81:2502-2509.

Kempson, S. A., and D. N. Logue. 1993. Ultrastructural observations of hoof horn from dairy cows: Changes in the white line during the first lactation. Vet. Rec. 132:524-527.

Lischer, Ch. J., U. Koller, H. Greyer, C. Mülling, J. Schulze, and P. Ossent. 2002. Effect of therapeutic dietary biotin on the healing of uncomplicated sole ulcers in dairy cattle-A double blind controlled study. Vet. J. 163:51-60.

McGeown, D., T. C. Danbury, A. E. Waterman-Pearson, and S. C. Kestin. 1999. Effect of carprofen on lameness in broiler chickens. Vet. Rec. 144:668-671.

Milligan, B. N., T. Duffield, and K. Lissemore. 2004. The utility of ketoprofen for alleviating pain following dehorning in young dairy calves. Can. Vet. J. 45:140-143.

National Research Council. 2001. Nutrient Requirements for Dairy Cattle. National Academy of Science, Washington, DC.

O'Callaghan, K. A., P. J. Cripps, D. Y. Downham, and R. D. Murray. 2003. Subjective and objective assessment of pain and discomfort due to lameness in dairy cattle. Anim. Welf. 12:605-610.

Owens, J. G., S. G. Kamerling, S. R. Stanton, and M. L. Keowen. 1995. Effects of ketoprofen and phenylbutazone on chronic pain and lameness in the horse. Equine Vet. J. 27:296-300.

Phillips, C. J. C. 1990. Adverse effects on reproductive performance and lameness of feeding grazing dairy cows partially on silage indoors. J. Agric. Sci. Camb. 115:253-258.

Rushen, J. 2001. Assessing the welfare of dairy cattle. J. Appl. Anim. Welf. Sci. 4:223-234.

Rushen, J., E. Pombourcq, and A. M. de Passillé. 2007. Validation of two measures of lameness in dairy cows. Appl. Anim. Behav. Sci. 106:173-177.

Rutherford, K. M. D. 2002. Assessing pain in animals. Anim. Welf. 11:31-53.

Ting, S. T. L., B. Earley, J. M. L. Hughes, and M. A. Crowe. 2003. Effect of ketoprofen, lidocaine local anaesthesia, and combined xylazine and lidocaine caudal epidural anesthesia during castration of beef cattle on stress responses, immunity, growth, and behavior. J. Anim. Sci. 81:1281-1293.

Whay, H. R., A. E. Waterman, A. J. F. Webster, and J. K. O'Brien. 1998. The influence of lesion type on the duration of hyperalgesia associated with hindlimb lameness in dairy cattle. Vet. J. 156:23-29. 